\title{
Coinfecções por hemoparasitos transmitidos por artrópodes em sete cães de uma propriedade rural no município de Mineiros-Goiás
}

\author{
Co-infections by arthropod-transmitted hemoparasites in seven dogs from a rural property in the \\ municipality of Mineiros-Goiás
}

Coinfecciones por hemoparásitos transmitidos por artrópodos en siete perros de una propiedad rural del municipio de Mineiros-Goiás

\author{
Iana Vilela Resende \\ ORCID: https://orcid.org/0000-0002-0063-5036 \\ Centro Universitário de Mineiros, Brasil \\ E-mail: iana_resende@hotmail.com \\ Isis Indaiara Golçalves Granjeiro Taques \\ ORCID: https://orcid.org/0000-0001-9616-5915 \\ Universidade Federal do Mato Grosso, Brasil \\ E-mail: isis_indaiara@hotmail.com \\ Samara Moreira Felizarda \\ ORCID: https://orcid.org/0000-0001-9253-8788 \\ Centro Universitário de Mineiros, Brasil \\ E-mail: samaramoreira55@hotmail.com \\ Dirceu Guilherme de Souza Ramos \\ ORCID: https://orcid.org/0000-0001-9603-6638 \\ Universidade Federal de Jataí, Brasil \\ E-mail: dgramos_vet@hotmail.com \\ Ísis Assis Braga \\ ORCID: https://orcid.org/0000-0001-5713-4833 \\ Centro Universitário de Mineiros, Brasil \\ E-mail: isis@unifimes.edu.br \\ Karla Irigaray Nogueira Borges \\ ORCID: https://orcid.org/0000-0003-3062-4829 \\ Centro Universitário de Mineiros, Brasil \\ E-mail:karla@unifimes.edu.br
}

\begin{abstract}
Resumo
As hemoparasitoses são enfermidades provocadas por patógenos distintos e propagadas por vetores hematófagos. Em meio a rotina clínica veterinária pode-se observar a importância destas doenças que acometem diferentes animais, apresentando sintomatologia variada, desde sinais brandos até sintomas mais graves, podendo até ocasionar o óbito do animal. Objetivou-se relatar no presente trabalho a coinfecção por hemoparasitos em cães, habitantes de uma propriedade rural no município de Mineiros-GO, sendo eles: Dirofilaria immitis, Hepatozoon sp., Trypanosoma evansi, Babesia sp. e Ehrlichia sp. e, ressaltando suas manifestações clínicas, achados laboratoriais e seus tratamentos. Os resultados dos exames laboratoriais, juntamente com os sinais clínicos apresentados demonstraram o quanto as hemoparasitoses podem afetar gravemente os animais com infecções concomitantes de difícil diagnóstico e sintomatologia inespecífica. Tornando assim fundamental a realização dos exames para um diagnóstico preciso, principalmente quanto a ocorrência destas coinfecções, possibilitando então um tratamento adequado e eficaz para o reestabelecimento da saúde e do bem-estar dos animais.
\end{abstract}

Palavras-chave: Babesiose; Dirofilariose; Erliquiose; Hemoparasitoses; Hepatozoonose; Tripanossomíase.

\begin{abstract}
Hemoparasitosis are diseases caused by different pathogens and spread by hematophagous vectors. In the midst of the veterinary clinical routine, it is possible to observe the importance of these diseases that affect different animals, presenting varied symptoms, from mild signs to more severe symptoms, which may even lead to the animal's death. The objective of this study was to report the clinical cases of seven animals, inhabitants of a rural property in the city of Mineiros-GO, affected by several hemoparasitosis, namely: Dirofilaria immitis, Hepatozoon sp., Trypanosoma evansi, Babesia sp. and Ehrlichia sp., highlighting their clinical manifestations, findings laboratory tests and their treatments. The results of laboratory tests, together with the clinical signs presented, demonstrated how much hemoparasitosis can seriously affect animals with concomitant infections that are difficult to diagnose and have non-
\end{abstract}


specific symptoms. This makes it essential to carry out examinations for a precise diagnosis, especially regarding the occurrence of these coinfections, thus enabling an adequate and effective treatment for the reestablishment of the animals' health and well-being.

Keywords: Babesiosis; Heartworm; Erlichiosis; Hemoparasitoses; Hepatozoonosis; Trypanosomiasis.

\section{Resumen}

Las hemoparasitosis son enfermedades causadas por diferentes patógenos y transmitidas por vectores hematófagos. En medio de la rutina clínica veterinaria, es posible observar la importancia de estas enfermedades que afectan a diferentes animales, presentando síntomas variados, desde signos leves hasta síntomas más severos, que incluso pueden llevar a la muerte del animal. El objetivo de este estudio fue reportar los casos clínicos de siete animales, habitantes de una propiedad rural en la ciudad de Mineiros-GO, afectados por varias hemoparasitosis, a saber: Dirofilaria immitis, Hepatozoon sp., Trypanosoma evansi, Babesia sp. y Ehrlichia sp., destacando sus manifestaciones clínicas. resultados de las pruebas de laboratorio y sus tratamientos. Los resultados de las pruebas de laboratorio, junto con los signos clínicos presentados, demostraron cuánto puede afectar gravemente la hemoparasitosis a los animales con infecciones concomitantes de difícil diagnóstico y sintomatología inespecífica. Esto hace imprescindible la realización de exámenes para un diagnóstico preciso, especialmente de la ocurrencia de estas coinfecciones, permitiendo así un tratamiento adecuado y eficaz para el restablecimiento de la salud y el bienestar de los animales.

Palabras clave: Babesiosis; Gusano del corazón; Ehrlichiosis; Hemoparasitosis; Hepatozoonosis; Tripanosomiasis.

\section{Introdução}

Os seres vivos no decorrer de sua vida possuem grande contato com diversos parasitos, podendo ocorrer infecções concomitantes por diferentes tipos em uma mesma amostra ou espécies diferentes e até mesmo parasitas de grupos taxonômicos distintos (Graham, Cattadori, Lloyd, Ferrari. \& Bjornstad, 2007).

As coinfecções possuem grande importância, mas constantemente são desconhecidas, pois agravam a doença e requerem abordagem clínica e prognóstico diferente do usual. As coinfecções podem causar maleficio para o seu hospedeiro, além de estar intimamente ligadas a fatores como nutrição, resposta imunológica, predomínio de doenças e intensidade da infecção (Lloyd, 1995).

As hemoparasitoses são causadas por parasitas que acometem as células do sistema hematopoiético dos animais. Podem ser bactérias ou protozoários que são capazes de colocar em risco a vida destes. Possuem diversos vetores, meios de transmissão, sinais clínicos e diferentes tratamentos (Breda, Rodrigues, Spada \& Torriani, 2018). Dentre a variedade de hemoparasitoses estudas, pode-se destacar: dirofilariose, hepatozoonose, tripanossomíase, babesiose e erliquiose.

A Dirofilariose é uma zoonose causada pela Dirofilaria immitis, um nematoide filarídeo transmitido por mosquitos (vetores) dos gêneros Culex, Aedes e Anopheles. É também denominada "verme do coração", o qual, quando adulto, parasita o coração de cães e outros mamíferos liberando suas larvas, chamadas de microfilárias, na corrente sanguínea (Silva \& Langoni, 2008).

A Hepatozoonose canina é causada, principalmente, pela espécie Hepatozoon canis, um protozoário parasita de leucócitos circulantes. Sua transmissão é por intermédio do carrapato, o qual é ingerido pelo cão (Lima et al., 2017).

A tripanossomíase é causada pelo Trypanosoma evansi, um protozoário transmitido por meio da picada do hospedeiro intermediário ou de forma direta. O hospedeiro final é um animal vertebrado, enquanto os vetores ou hospedeiros intermediários são diversos invertebrados hematófagos (Silva, Seidi, Ramirez, \& Dávila, 2002).

A babesiose canina é uma doença causada por um protozoário do gênero Babesia, conhecida como piroplasmose canina, de característica hemolítica, transmitida pelo carrapato Rhipicefalus sanguineus (Brandão \& Hagiwara, 2002).

A erliquiose canina é causada por uma bactéria intracelular obrigatória do gênero Ehrlichia, principalmente pela espécie Ehrlichia canis, agente etiológico da erliquiose monocítica canina (EMC). Também transmitida pelo carrapato e distribuída em quase todo Brasil. Possui sintomatologia inespecífica, o diagnóstico é feito com a junção dos sinais clínico e achados laboratoriais (Andereg \& Passos, 2017). 
Estas doenças são muitas vezes sub diagnosticadas na rotina clínica veterinária, tardando assim o tratamento efetivo e a recuperação do animal. O presente trabalho tem como objetivo relatar os casos clínicos de sete animais acometidos por diferentes hemoparasitos, em propriedade na zona rural do município de Mineiros, estado de Goiás.

\section{Revisão de Literatura}

\subsection{Dirofilariose}

As dirofilárias se encontram presentes na família Filariidae, subfamília Dirofilarinae, gênero Dirofilaria, e possui dois subgêneros a Dirofilaria e a Nochtiella. No subgênero Dirofilaria tem-se a Dirofilaria immitis e no subgênero Nochtiella a Dirofilaria ursi, Dirofilaria tenuis e Dirofilaria repens, sendo todos capazes de infectar o ser humano (Silva \& Langoni, 2008). Esta doença é considerada cosmopolita, mas é principalmente encontrada em zonas quentes propícias para o crescimento do vetor (Alho, Meireles, Belo \& Carvalho, 2014).

O ciclo biológico da Dirofilaria immitis é indireto e heteroxeno com cinco estágios larvais, sendo três destes estágios em um hospedeiro intermediário (HI) como os artrópodes da família Culicidae e os outros dois estágios em um hospedeiro definitivo (HD) vertebrado (Oliveira et al., 2016). A transmissão ocorre através da picada do mosquito susceptível (da família Culicidae em um hospedeiro parasitado, o qual se infecta e após o desenvolvimento larval e um novo repasto sanguíneo em um hospedeiro definitivo, este é disseminado (Leite et al., 2006).

A maioria dos animais acometidos não apresenta sinais clínicos específicos, normalmente manifestam-se de acordo com a quantidade de dirofilárias no coração e da resposta imunológica do hospedeiro. É comum o aparecimento de sintomas como dispneia, tosse, infecções pulmonares, perda de peso, anemia, ascite, caquexia, insuficiência cardíaca congestiva, síndrome da veia cava, sons pulmonares anormais, glomerulonefrite pela deposição de imunocomplexos, alongamento da veia jugular, gerando hepatomegalia e esplenomegalia (Bowman et al., 2014).

O diagnóstico da dirofilariose é baseado na sintomatologia, presença da microfilária no esfregaço sanguíneo, técnica de Knott, testes imunodiagnósticos, técnica da gota espessa, PCR, ecocardiograma e radiografia do tórax também são realizados e auxiliam no diagnóstico (Monteiro, 2014). Para os animais assintomáticos são indicados exames de imagem como raio-x, onde será possível visualizar o espessamento da artéria pulmonar, angiografia para apresentar as alterações vasculares e a necropsia para visualização da presença dos vermes nas câmaras cardíacas (Taylor, Coop, \& Wall, 2014).

Devido ao risco resultante do tratamento, a eliminação excessiva de vermes que pode causar tromboembolismo e choque anafilático, é recomendada a eliminação gradual destes (Simón et al., 2012). Objetivando a erradicação dos vermes do coração, nos tratamentos adulticidas são utilizados o dicloridrato de melarsomina e etiacetarsamida (Almosny, 2002). A associação de ivermectina com a doxiciclina também tem obtido um prognóstico satisfatório (Silveira, 2018). O uso de lactonas macrocíclicas (ivermectina ou milbemicina) antes da administração dos adulticidas é recomendado, pois estas albergam as larvas de menor idade (Nelson, 2015). Entretanto, para diminuir o risco de reações adversas pelo uso de medicamentos é recomendado a remoção das filárias através de cirurgia e o uso de tratamento profilático posteriormente (Taylor et al., 2014).

Para o controle da doença, é fundamental um diagnóstico certeiro juntamente com um tratamento eficaz dos animais acometidos, conscientização da população sobre a enfermidade, identificação de cães acometido, mosquitos portadores e medidas de saneamento (Leite et al., 2006). Algumas medidas de precaução podem ser tomadas, como o uso de soluções tópicas (repelentes) no animal para evitar o contato do vetor (Silva \& Langoni, 2008). 


\subsection{Hepatozoonose}

A hepatozoonose foi primeiramente relatada em 1906 na Índia, onde recebeu o nome de Leukocytozoon canis. O gênero Hepatozoon spp. é pertencente ao reino Protozoa, filo Apicomplexa, classe Sporozoa, subclasse Coccidia, ordem Eucoccidiida e a família Hepatozoidae (Mathew et al., 2000). Até então, foram reconhecidas duas espécies de Hepatozoon spp., sendo elas o Hepatozoon canis e o Hepatozoon americanum, distintos, principalmente, por sua distribuição geográfica, onde são encontradas referências do H. canis na Europa, África, Ásia e América do Sul e o H. americanum no sul dos Estados Unidos (Vicent-Johnson et al., 1997; Baneth et al., 2000). Esta enfermidade é encontrada, frequentemente, em estações do ano com altas temperaturas devido à presença de carrapatos (Lima et al., 2017).

O ciclo biológico do Hepatozoon spp. abrande dois hospedeiros, sendo o carrapato o hospedeiro definitivo (HD), com o seu ciclo realizado por meio da singamia e o cão como hospedeiro intermediário (HI), mediante a reprodução assexuada (Taylor et al., 2014). A transmissão acontece a partir da ingestão do carrapato contendo oocistos maduros na sua hemocele, possuindo como principais vetores o Rhipicephalus sanguineus e Amblyomma spp. A ingestão pode acontecer por intermédio de lambeduras ou pela presença de carrapatos que caíram no seu alimento em ambientes infestados e após alcançar a circulação sanguínea o agente irá parasitar neutrófilos e monócitos circulantes (Aguiar et al., 2004).

Os animais parasitados manifestam sintomas inespecíficos, podendo ainda serem assintomáticos. Os sintomas mais relatados são febre, perda de peso, anemia, descarga ocular, fraqueza, letargia, diarreia e incoordenação motora (Mundim, Mundim \& Barbosa, 2002). Em sua maioria os cães infectados são imunossuprimidos, possuindo infecções concomitantes (Melo, Miranda, Almeida, Albernaz, \& Machado, 2008).

O seu diagnóstico é baseado na visualização de gametócitos nas células de defesa no esfregaço sanguíneo ou pela visualização do microrganismo na musculatura em cortes de biopsia. O diagnóstico presuntivo é identificado com leucocitose neutrofílica com desvio a esquerda, eosinofilia e anemia (Ettinger \& Feldman, 2014) e índices elevados de gama glutamil transferase (GGT) e fosfatase alcalina (FA) devido à hepatite secundária causada pelo agente (Aguiar et al., 2004). Também podem ser utilizados testes sorológicos de Reação de Imunofluorescência Indireta (RIFI) e PCR (Inokuma, Okuda, Ohno, Shimoda \& Onishi, 2002).

No tratamento de eleição da hepatozoonose utiliza-se o dipropionato de imidocarb associado à doxiciclina ou tetraciclina (Almenara, Cerri, Garcia, \& Neves, 2008). Os anti-inflamatórios não esteroidais são utilizados como suporte para febre e dor (Voyvoda, Pasa \& Uner, 2004). A prevenção é realizada com medicamentos acaricidas e a cautela com a presença de carrapatos nos animais (Taylor et al., 2014). Atualmente são utilizados inseticidas e repelentes em coleiras e sprays, elaborados com permetrinas, fipronil, amitraz e imidaclopride. Também deve-se evitar a aproximação dos animais em lugares infestados de carrapatos (Solano-Gallego \& Baneth, 2011).

\subsection{Tripanossomíase}

De acordo com Michels e Hannaert (1994) a tripanossomíase conhecida como "mal das cadeiras" é causada por um agente que pertence à classe Kinetoplastida, família Trypanosomatidade, gênero Trypanosoma e espécie Trypanosoma evansi. É um protozoário transmitido por meio da picada do hospedeiro intermediário ou de forma direta. Pode acometer, além dos equinos, bovinos, antas, cães, suínos, caprinos, veados, capivaras, quatis, zebuínos, búfalos e pequenos roedores silvestres (Silva, Ceolin, Oliveira, Monteiro, \& Doyle, 2007). Encontrado em áreas de climas tropicais e subtropicais, é considerada endêmica no Pantanal Sul Mato-grossense, o qual atinge, principalmente, os equinos (Silva, Seidi, Ramirez, \& Dávila, 2002).

O seu ciclo biológico se dá a partir dos insetos hematófagos das famílias Stomaxidae e Tabanidae ou por morcegos hematófagos (Desmodus rotundus). Estes transmitem o parasita através da saliva durante o repasse sanguíneo para um hospedeiro vertebrado (Monteiro, 2014). Além de insetos e morcegos, a transmissão se dá pela forma iatrogênica e por meio de 
fômites. Os cães podem ainda ser acometidos por meio de contato direto com carcaças de animais portadores (Raina, Kumar, Rajora, Sridhar, \& Singh, 1985). De acordo com Herrera et al. (2004) os cachorros, capivaras e quatis também podem contrair esta enfermidade através de brigas com animais já infectados.

Os sinais surgem especialmente na fase aguda, sendo destacados: febre, edema subcutâneo, anemia, letargia, apatia e perda de coordenação motora. Na fase subaguda, o animal é assintomático, mas na fase crônica, os sintomas são intensificados, apresentando mucosas pálidas e/ou ictéricas, paralisia dos membros posteriores e linfonodos aumentados podendo levar a morte. A anemia é comum neste quadro, as proteínas plasmáticas podem apresentar possível aumento devido à grande produção de imunoglobulinas (Conrado et al., 2005).

O diagnóstico é realizado a partir do hemograma com visualização do parasita na lâmina. O PCR e outros exames sorológicos distinguem a espécie encontrada (Milocco et al., 2012). O tratamento é, principalmente, à base de aceturato de diminazeno, podendo associá-lo com a oxitetraciclina (Doyle, Silva, Monteiro, Santurio, \& Graça, 2007).

\subsection{Babesiose}

A babesiose canina é causada por um protozoário que parasita hemácias de diversos animais e de humanos, denominado Babesia canis. Foi primeiramente encontrado na Itália, e posteriormente na Ásia, Europa, África e América (Antoni, Oliveira, \& Zappa, 2009). É pertencente ao filo Apicomplexa, classe Sporozoasida, ordem Piroplasmorida e família Babesiidae (Taylor et al., 2014).

A espécie de carrapato Rhipicephalus sanguineus, também conhecido como carrapato marrom do cão, desencadeia a transmissão da babesiose no cão, havendo também a possibilidade de infecção por transfusões sanguíneas. O seu ciclo se inicia no momento em que o carrapato infectado realiza o repasto sanguíneo em um cão sadio, até a invasão dos eritrócitos (Chauvin et al., 2009).

As manifestações clínicas diversificam-se de acordo com a apresentação da doença: subclínica, hiperaguda, aguda e crônica (Corrêa, Nascimento, \& Faria, 2005). Os sinais clínicos apresentados são de acordo com a hemólise causada pelo parasita (Brandão \& Hagiwara, 2002). Na fase aguda se observa: febre, mucosas pálidas, icterícia, apatia, anorexia, prostração, diarreia, esplenomegalia, sinais neurológicos, podendo até levar à morte. Na forma hiperaguda, a caracterização se dá por choque hipovolêmico, ferimentos teciduais, hipóxia e morte, esta forma acomete comumente filhotes de mães infectados. Já na forma crônica são observadas diminuição de apetite, edema, perda de peso, febre casual, fraqueza, esplenomegalia, evidenciando os sinais hepáticos no estágio final (Nelson \& Couto, 2001). Nas alterações hematológicas observa-se primeiramente, anemia normocítica e normocrômica devido ao tempo insuficiente de resposta medular e trombocitopenia. A variação de leucócitos é normal, estes podem estar diminuídos ou aumentados (Braga \& Silva, 2013).

Seu diagnóstico é feito por meio da visualização do protozoário no esfregaço sanguíneo ou outros testes mais sensíveis como o Ensaio de Imunoabsorção Enzimática (ELISA), a Imunofluorescência (RIFI) ou o PCR. O principal fármaco utilizado no tratamento é o dipropionato de imidocarb (Dias \& Ferreira, 2016). A prevenção é, principalmente, realizada a partir do controle do vetor nos animais e no ambiente (Monteiro, 2014).

\subsection{Erliquiose}

A erliquiose é causada por bactérias Gram negativas pertencentes à ordem Rickettsiales, família Rickttsiaceae, gênero Ehrlichia spp. São parasitas intracelulares obrigatórios que infectam os leucócitos sanguíneos na forma de inclusões intracitoplasmáticas transmitidas pelo carrapato (Taylor et al., 2014). Foi descrita pela primeira vez no Brasil em 1973, por Costa, no estado de Minas Gerais (Costa et al., 1973). 
A transmissão entre os animais é realizada por meio do repasto sanguíneo do carrapato Rhipicephalus sanguineus infectado em um cão hígido. No carrapato ocorre a transmissão transestadial (da bactéria presente nas larvas, para as fases de ninfa e adultos), e no cão existem casos de transmissão pela transfusão sanguínea de animais infectados para animais sadios (Monteiro, 2014).

A doença possui três fases descritas: a subclínica, aguda e crônica. Os sinais apresentados na fase aguda são febre, apatia, trombocitopenia, anemia arregenerativa e anorexia. Na fase subclínica o animal pode ser assintomático ou apresentar sintomas brandos, como perda de peso. Na fase crônica os sintomas podem estar ausentes ou serem agravados, exibindo pancitopenia e hemorragias, além de possuir maior susceptibilidade a infecções secundárias (Isola, Cadioli, \& Nakage, 2012).

O diagnóstico da erliquiose é feito através da anamnese, presença do vetor no animal, visualização das mórulas no esfregaço sanguíneo, dosagem da titulação de anticorpos, testes rápidos e pela PCR (Sousa et al., 2010).

No mercado existem várias drogas eficazes para o tratamento da erliquiose como: tetraciclina, doxiciclina, minociclina, oxitetraciclina e cloranfenicol. Porém, o fármaco de eleição, em todas as fases da doença é a doxiciclina. Além da utilização de terapias suporte nos casos de anemia grave ou no acometimento de outros órgãos (Silva, Fernandes, Nogueria, \& Ambrosio, 2011). A profilaxia desta enfermidade, assim como nas outras doenças transmitidas pelo carrapato, é feita a partir do controle do vetor no ambiente e no animal (Almosny, 2002).

\section{Metodologia}

Foram atendidos, no ano de 2019, em uma propriedade rural do município de Mineiros-GO sete cães, sendo seis da raça Americana e um Pit Bull, entre estes, quatro machos e três fêmeas possuindo idades entre 2 e 4 anos. Durante a anamnese o proprietário relatou que os cães eram utilizados para caça de animais silvestres e que alguns animais apresentavam apatia, perda de peso e prostração. A propriedade possuía condições de higiene precárias e presença de diversos vetores, os cães viviam em um canil feito de madeira próximo a sede, com alimentação a vontade e água em condições inadequadas de limpeza. Ao exame clínico os animais apresentaram em sua maioria: taquicardia, taquipneia, dor à palpação abdominal, mucosas hipocoradas, presença de ectoparasitas (carrapatos) e lesões cutâneas alopécicas ocasionadas pelo prurido intenso, além de sinais de subnutrição como anorexia e desidratação.

Foram coletadas amostras de sangue através da venopunção cefálica, em tubos contento EDTA para realização de hemograma com pesquisa de hemoparasitos no esfregaço e na capa leucocitária e PCR (Reação em Cadeia pela Polimerase).

Os hemogramas foram realizados por contagem eletrônica no Analisador Celltac $\alpha$ MEC - Nihon Kohden de acordo com os valores de referência de Meyes \& Harvey (2004) e Jain (1993).

\section{Resultados}

Nos esfregaços foram observados, através da pesquisa de hemoparasitos, a presença de Trypanosoma spp. (Figura 1) em dois animais, de Hepatozoon spp. (Figura 2) em cinco animais e de microfilárias de Dirofilaria immitis (Figura 3) em um animal.

O sangue total foi submetido à extração de DNA utilizando o kit comercial Wizard® Genomic DNA Purification Kit, de acordo com as normas do fabricante para a PCR. As amostras foram testadas para Trypanosoma evansi (identificação da espécie), Hepatozoon spp., Babesia spp. e Ehrlichia spp. (identificação do agente) de acordo, respectivamente, com o protocolo de Claes et al. (2004), Criado-Fornelio et al. (2006), Almeida, Souza, Marcili e Labruna (2013) e Doyle et al. (2005).

A partir dos resultados dos exames, iniciaram-se os tratamentos para Trypanosoma evansi com aceturato de diminazeno (Beroseg ${ }^{\circledR} 7 \%$ ), 3,5 mg/kg, via intramuscular, dose única. Os animais com Hepatozoon spp. tiveram a prescrição 
de Doxiciclina (Doxifin $\left.{ }^{\circledR}\right) 5 \mathrm{mg} / \mathrm{kg}$, via oral, de $12 \mathrm{em} 12$ horas, durante 21 dias; dipropionato de imidocarb (Imizol $\left.{ }^{\circledR}\right) 5 \mathrm{mg} / \mathrm{kg}$, via subcutânea, duas aplicações, a cada 14 dias, sendo administrado atropina (Atropina 1\% Fagra ${ }^{\circledR}$ ) 15 minutos antes. Para o cão com microfilárias de Dirofilaria immitis foi prescrito melarsomida (Immiticide ${ }^{\circledR}$ ) 2,5 mg/kg, intramuscular, duas doses com intervalo de 24 horas e ivermectina com pamoato de pirantel (Biotril ${ }^{\circledR}$ ), via oral, 1 comprimido para os cães entre 10$20 \mathrm{~kg}$, também foi solicitado exame de imagem (raio-x).

O prognóstico da maioria dos animais era favorável, entretanto após a indicação dos medicamentos o proprietário não retornou para nova consulta e nem apresentou os exames solicitados.

Figura 1 - Trypanosoma spp. de um dos cães visualizado no esfregaço com a objetiva de imersão de 100X, em uma propriedade rural de Mineiros-GO, corado com panótico rápido.

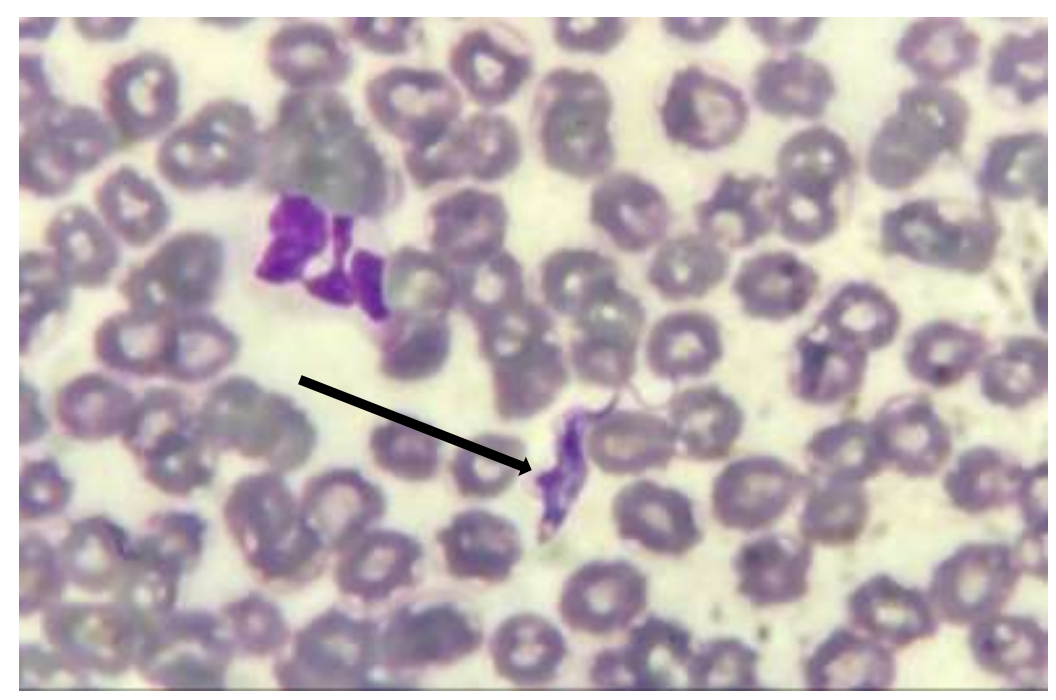

Fonte: Arquivo pessoal.

Figura 2 - Hepatozoon spp. de um dos cães visualizado no esfregaço com a objetiva de imersão de 100X, em uma propriedade rural de Mineiros-GO, corado com panótico rápido.

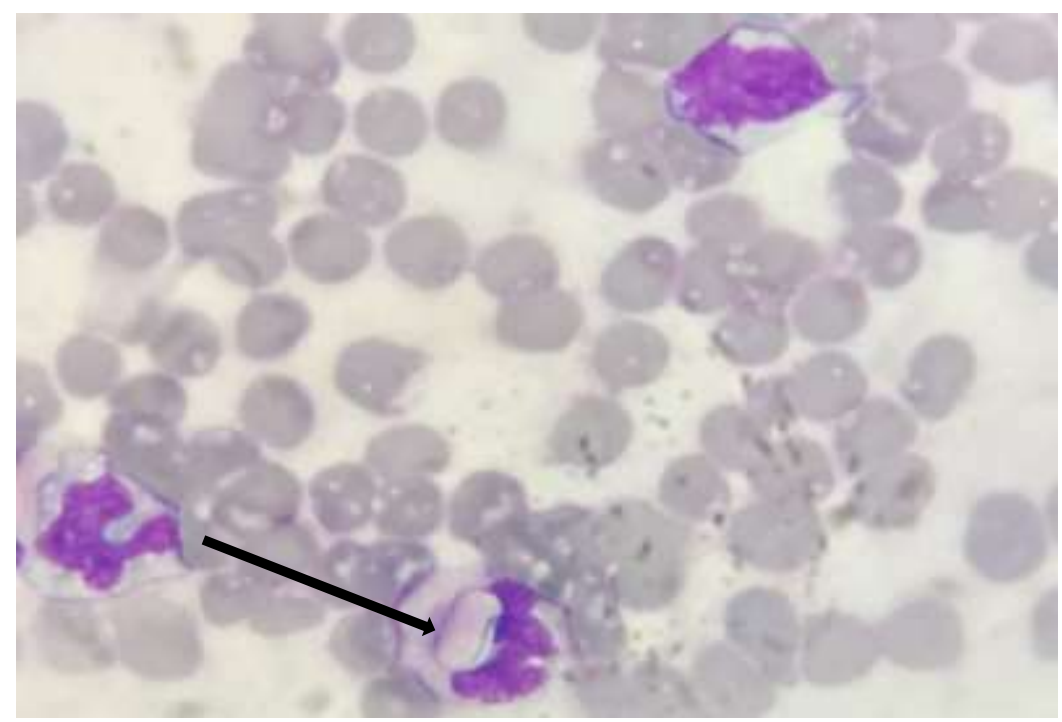

Fonte: Arquivo pessoal. 
Research, Society and Development, v. 10, n. 12, e393101220294, 2021

(CC BY 4.0) | ISSN 2525-3409 | DOI: http://dx.doi.org/10.33448/rsd-v10i12.20294

Figura 3 - Microfilária de Dirofilaria immitis de um cão visualizada no esfregaço com a objetiva de imersão de 100X, em uma propriedade rural de Mineiros-GO, corado com panótico rápido.

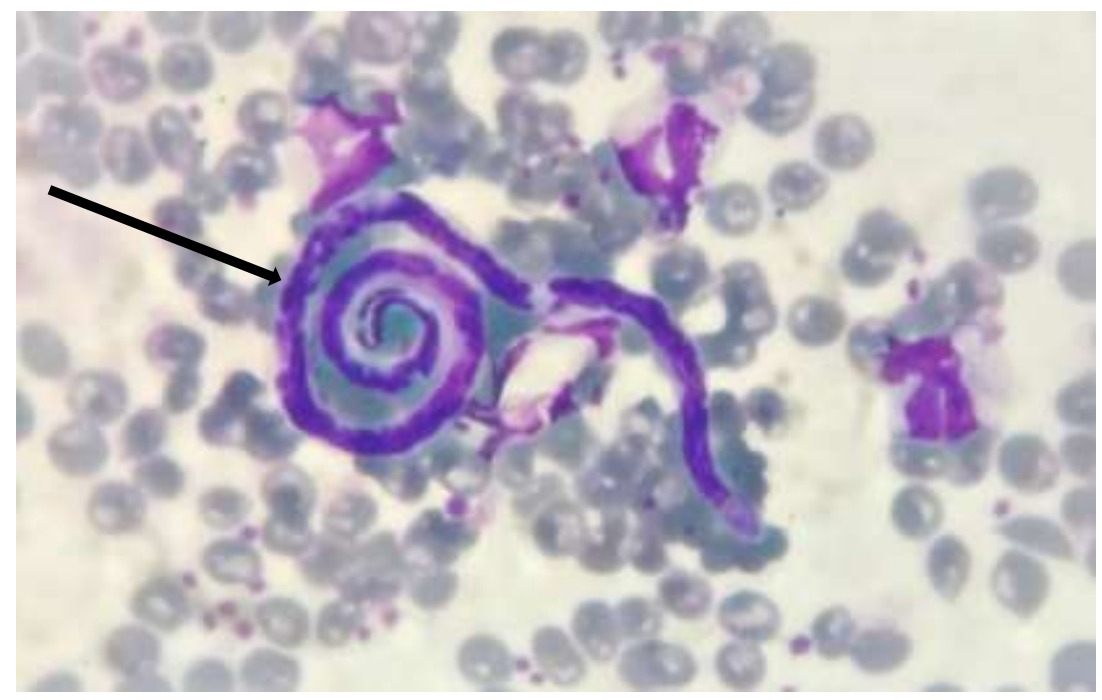

Fonte: Arquivo pessoal. 


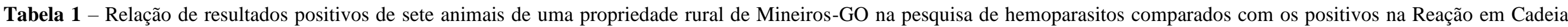
pela polimerase, sinais clínicos apresentados no exame físico e achados hematológicos

\begin{tabular}{|c|c|c|c|c|}
\hline ANIMAL & SINAIS CLÍNICOS & ACHADOS HEMATOLÓGICOS & $\begin{array}{l}\text { PESQUISA DE } \\
\text { HEMATOZOÁRIOS }\end{array}$ & PCR \\
\hline 1 & $\begin{array}{l}\text { Taquicardia, taquipneia, mucosas hipocoradas, } \\
\text { presença de lesões pelo corpo e dor a palpação }\end{array}$ & $\begin{array}{c}\text { Intensa anemia com moderada anisocitose e } \\
\text { policromasia e trombocitopenia }\end{array}$ & Trypanosoma sp. & Trypanosoma evansi \\
\hline 2 & $\begin{array}{c}\text { Taquicardia, taquipneia ofegante, linfoadnomegalia, } \\
\text { mucosa ocular congesta, dor a palpação abdoinal e } \\
\text { presença de carrapatos }\end{array}$ & $\begin{array}{c}\text { Intensa anemia com leve anisocitose e policromasia, } \\
\text { trombocitopenia e leucopenia por neutropenia, com } \\
\text { presença de linfócitos reativos }\end{array}$ & Hepatozoon sp. & $\begin{array}{c}\text { Hepatozoon sp., Babesia sp. e } \\
\text { Ehrlichia sp. }\end{array}$ \\
\hline 3 & $\begin{array}{l}\text { Taquipneia, dor a palpação abdominal e presença de } \\
\text { carrapatos }\end{array}$ & $\begin{array}{l}\text { Leve anemia com leve anisocitose e policromasia, } \\
\text { leucograma com presença de linfócitos reativos e } \\
\text { trombocitopenia }\end{array}$ & $\begin{array}{l}\text { Trypanosoma sp. e } \\
\text { Hepatozoon sp. }\end{array}$ & Trypanosoma evansi \\
\hline 4 & $\begin{array}{c}\text { Mucosas hipocoradas, dor a palpação abdominal e } \\
\text { presença de carrapatos }\end{array}$ & $\begin{array}{l}\text { Moderada anemia normocíticas e normocrômicas, } \\
\text { trombocitopenia e hipoproteinemia }\end{array}$ & Hepatozoon sp. & Hepatozoon sp. e Babesia sp. \\
\hline 5 & $\begin{array}{c}\text { Taquipneia, mucosa oral e ocular hipocoradas, } \\
\text { alopecia e presença de carrapatos }\end{array}$ & $\begin{array}{c}\text { Moderada anemia com moderada anisociose e } \\
\text { policromasia, leucograma com neutropenia e linfocitose } \\
\text { e trombocitopenia }\end{array}$ & Hepatozoon sp. & Hepatozoon sp. \\
\hline 6 & Taquipneia e presença de carrapatos & Leucopenia por neutropenia & $\begin{array}{l}\text { Microfilária de } \\
\text { Dirofilaria immitis }\end{array}$ & - \\
\hline 7 & $\begin{array}{c}\text { Taquicardia, taquipneia, dor a palpação abdominal e } \\
\text { presença de carrapatos }\end{array}$ & Trombocitopenia & Hepatozoon sp. & Hepatozoon sp. \\
\hline
\end{tabular}

Fonte: Autores. 
Na tabela acima pode-se observar que além dos hemoparasitos encontrados na lâmina, foram diagnosticados através da PCR mais dois agentes. Os sinais clínicos apresentados foram, em sua maioria, aumentos da frequência respiratória e cardíaca, dor a palpação abdominal, presença de carrapatos e mucosas pálidas. E os achados hematológicos, no geral, foram anemia, leucopenia e trombocitopenia.

\section{Discussão}

Foi observado que na maioria dos animais haviam coinfecções não relatas na pesquisa de hemoparasitos, as quais estavam influenciando na sintomatologia e, consequentemente, no tratamento dos animais. Os achados hematológicos e os sinais clínicos, em sua maioria, foram variados, mesmo apresentando infecção pelo mesmo parasito.

Patógenos distintos podem parasitar o mesmo hospedeiro concomitantemente, intervindo de maneira indireta ou direta um ao outro. As coinfecções são dependentes das interações entre os patógenos atuantes e interações entre eles. Portanto, os sinais clínicos apresentados por um parasita em um hospedeiro coinfectado com outro parasita ou outra espécie, pode ser totalmente diferente dos sinais clínicos causados por esse parasita em um hospedeiro não coinfectado (Cox, 2001).

São raros os relatos de coinfecções entre as doenças descritas no trabalho, principalmente a tripanossomíase associada com a hepatozoonose, embora seja uma suspeita frequente em animais de zona rural utilizados para caça de animais silvestres, como é o retratado neste.

O Trypanosoma evansi empregou uma certa predileção por cães de zona rural e destinados a caça, devido ao meio de transmissão ser justamente ocasionado pela diversidade dos hospedeiros que podem ser acometidos, desde animais domésticos até animais silvestres tidos como reservatórios da doença. A presença de vários tipos de vetores triatomíneos também é mais frequente nestes locais, o que influência no fato da doença não depender da predileção do mosquito, visto que são diversos que podem transmiti-la (Araújo, Jansen, Reinhard, \& Ferreira, 2009; Halkyer \& Torres, 2010).

Os casos de Dirofilariose canina são frequentemente relatados em regiões litorâneas, devido à multiplicação do vetor (Brito, et al. 2001). Porém, no presente trabalho, a infecção ocorreu no município de Mineiros, interior de Goiás, onde a infecção possui baixa incidência. Em lugares que possuem clima e ambiente propício, é possível o desenvolvimento do vetor. As mudanças epidemiológicas da enfermidade podem ser em decorrência das alterações climáticas, a migração de animais infectados para áreas onde não haviam relatos da doença, a grande incidência de animais abandonados e a escassez de prevenção e controle (Mupanomunda, Williams, Mackenzie, \& Santos, 2017).

No leucograma do animal com microfilária de $D$. immitis foi observado a presença de leucopenia por neutropenia. Contrariando Pimentel, Barbosa e Ferrer (2013), o qual, relatou que animais com dirofilariose podem manifestar neutrofilia relativa, eosinofilia e linfopenia. Acredita-se que a baixa resposta imune do animal diante da hemoparasitose seja devido ao estado nutricional dos animais.

Os animais infectados com T. evansi apresentaram anemia intensa e trombocitopenia, Aquino et al (2002) afirma que a tripanossomíase ainda não tem sua patogenia elucidada. No entanto, a anemia é o principal achado e se dá a partir da intensa lise de eritrócitos nos pulmões, medula, baço, fígado, linfonodos e principalmente na circulação, visto que, o parasita se adere aos eritrócitos e provocam uma resposta imune tornando-as susceptíveis a fagocitose (Silva, Costa, Lopes, \& Monteiro, 2008).

Sabe-se que algumas hemoparasitoses, como a hepatozoonose, não apresentam sintomatologia aparente. No entanto, quando há ocorrência de coinfecção com a E. canis e a Babesia spp. pode-se alterar diretamente a sua patogenicidade (Harrus \& Waner, 2011). Apresentando então, sinais clínicos mais severos e inespecíficos com um prognóstico reservado (Mylonakis, koutinas, Baneth, Polizopoulou, \& Fytianou, 2004).

De acordo com os estudos de Costa (2011), animais trombocitopênicos são seis vezes mais predispostos a terem infecções mistas. Portanto, ao apresentarem coinfecções é normal que sejam concomitantes com trombocitopenia, 
principalmente em cães que tenham como um dos diagnósticos positivo para erliquiose. Além do mais, há uma certa dificuldade em correlacionar alterações clínicas e hematológicas provenientes de infecções simples e de coinfecções, por serem comuns às doenças ocorrentes (Yabskley et al., 2008). Observando os sinais apresentados pelos animais com hepatozoonose pode-se confirmar o que os autores já citados relataram, pois estes manifestaram sintomas inespecíficos e todos apresentaram trombocitopenia, fato explicado pelas coinfecções detectadas na PCR.

Em relação aos tratamentos, algumas coinfecções possuem recursos terapêuticos similares dependendo de fármacos protozoocidas. Almosny (2002) evidencia a importância do diagnóstico para começar o tratamento, pois a maior patogenicidade de alguns parasitas faz com que alguns animais acabem não respondendo bem às terapias. Defendendo que quanto maior o nível de parasitemia, maior a dificuldade encontrada em fazer o tratamento correto com eficiência.

O tratamento da tripanossomíase consistiu no fornecimento do aceturato de diminazeno (Beroseg® ${ }^{\circledR} \%$ ) ao animal, sendo este o de predileção para o controle do protozoário (Silva et al. 2010). No entanto, optou-se pela associação com o dipropionato de imidocarb $\left(\mathrm{Imizol}^{\circledR}\right)$ devido a coinfecção com o Hepatozoon spp., relatado em um dos animais, não tendo correlação alguma com a eficácia do tratamento para a tripanossomíase, levando em questão, a consideração feita por Silva et al. (2008) de que o dipropionato de imidocarb $\left(\operatorname{Imizol}^{\circledR}\right)$ não seja mesmo eficaz para o T. evansi.

Para a dirofilariose foi receitado a melarsomida $\left(\operatorname{Immiticide}^{\circledR}\right)$, que embora seja mais utilizada, não é isenta de efeitos adversos, levando em consideração a patogenia da doença, onde a morte das larvas pode ocasionar um quadro de tromboembolismo. Por esse motivo, o animal não deve ser submetido a quaisquer exercícios físicos após a administração do fármaco, assim, poupando esforço para menor sofrimento quanto aos sintomas respiratórios e circulatórios (Ettinger \& Feldman, 2014). Fato ressaltado ao proprietário durante a prescrição do tratamento.

A prevenção e controle dos hemoparasitos deve ser preconizada a partir da limpeza do local onde se encontra os animais, uso de medicamentos preventivos contra os vetores artrópodes e um bom controle estratégico dos vetores com parasiticidas, tornando mais dificultoso o acometimento dos protozoários aos animais (Silva, Lima, Ramirez, \& Dávila, 2004). Os pontos expostos acima fizeram parte das orientações propostas ao proprietário para eficácia dos tratamentos e melhorias nas condições sanitárias do ambiente e por consequência dos animais.

A reação em cadeia da polimerase (PCR) é uma técnica molecular biológica, que consiste no reconhecimento de agentes a partir do seu DNA, fazendo com que se tenha um diagnóstico rápido e preciso devido à sua alta especificidade (Haas \& Torres, 2016). Importante método utilizado no presente trabalho, pois possibilitou a identificação das coinfecções de Babesia spp. e Ehrlichia spp., as quais não foram observadas no esfregaço sanguíneo.

\section{Conclusão}

Sendo assim, a identificação das coinfecções na propriedade relatada, evidenciou que além do alto índice de animais positivos para as referidas hemoparasitoses, destaca-se também que o meio insalubre, com condições de higiene precárias e presença de vetores, habitado por esses cães contribuiu diretamente para o agravo das enfermidades.

Os resultados demonstraram a importância de adequada investigação clínica, epidemiológica e laboratorial para a identificação das doenças, das fontes de infecção, modos de transmissão, fatores de risco e predisposições individuais. Pois somente desta forma foi possível comprovar a ocorrência das infecções concomitantes relatadas no presente trabalho.

Foi evidenciado que o diagnóstico preciso é essencial para auxiliar o clínico nas decisões sobre condutas a serem tomadas principalmente em relação ao tratamento a ser prescrito. Desde forma, resultando na melhora do animal e de suas condições de vida. 


\section{Referências}

Andereg, P. I. \& Passos, L. M. F. (1999). Canine ehrlichiosis - a review. Revista Clínica Veterinária, (19), 31-38.

Aguiar, D. M., Ribeiro, M. G., Silva, W. B., Dias, J. G., Jr., Megid, J., \& Paes, A. C. (2004). Hepatozoonose canina: Achados clínico-epidemiológicos em três casos. Arquivo Brasileiro de Medicina Veterinária e Zootecnia, 56(3), 411-413.

Alho, A. M., Meireles, J., Belo, S., \& Carvalho, L. M. (2014). Dirofilariose canina e felina, uma parasitose em evolução (I) - etiologia, biologia e epidemiologia. Clínica Animal, 2(1), 20-25.

Almeida, A. P., Souza, T., Marcili, A., \& Labruna, M. B. (2013). Novel Ehrlichia and Hepatozoon agents infecting the crab-eating fox (Cerdocyon thous) in southeastern Brazil. Journal of Medical Entomology. (50), 640-646.

Almenara, F. S., Cerri, F., Garcia, P. V., \& Neves, M. F. (2008). Hepatozoonose. Revista Científica Eletrônica de Medicina Veterinária, 6(11).

Almosny, N. R. P. Hemoparasitoses em pequenos animais domésticos e como zoonoses. L.F. Livros de Veterinária Ltda., 2002. p.112-126.

Antonio, N. S., Oliveira, A. C., \& Zappa, V. (2009). Babesia canis: Relato de caso. Revista Científica Eletrônica de Medicina Veterinária, 7(12), 12-15.

Aquino, L. P.C. T., Machado, R. Z., Alessi, A. C., Santana, A. E., Castro, M. b., Marques, L. C., \& Malheiros, E. B. (2002). Hematological biochemical and anatomopathological aspects of the experimental infection with Trypanosoma evansi in dogs. Arquivo Brasileiro de Medicina Veterinária e Zootecnia, 54(1), $8-18$

Araújo, A., Jansen, A. M., Reinhard, K., \& Ferreira, L. F. (2009). Paleoparasitology of Chagas disease - a review. Memórias Instituto Oswaldo Cruz, 104, 916.

Baneth, G., Barta, J. R., Shkap, V., Martin, D. S., Macintire, D. K., \& Vicent-Johnson, N. (2000). Genetic and antigenic evidence supports the separation of Hepatozoon canis and Hepatozoon americanum at the species level. Journal of Clinical Microbiology, 38(3), $1298-1301$.

Braga, J. F. V., \& Silva, S. M. M. S. (2013). Babesiose canina: uma visão geral da doença. Revista de Ciências Agroveterinárias, $12(2), 204-213$.

Brandão, L. \& Hagiwara, M.K. (2002). Babesiose canina: revisão. Clínica Veterinária, (41), 50-59.

Bowman, Dwight D. G. (2010) - Parasitologia Veterinária. (9a ed.), Elsevier; 202-207.

Breda, J. C., Rodrigues, A. D., Spada, P. K. W. D. S. \& Torriani, T. (2018). Hemoparasitoses em cães: análise de dados laboratoriais. Revista acadêmica de Ciências animais, 16, 2-3.

Brito, A. C. et al., (2001). Prevalência da filariose canina causada por Dirofilaria immitis e Dipetalonema reconditum em Macéio, Alagoas, Brasil. Cad. Saúde Pública, 17, 1497-1504.

Chauvin, A et al., (2009). Babesia and ist rost: adaptation to long-lasting interactions as a way to achieve eficiente trensmission. Veterinary Research. v.40:37.

Claes, F., Radwanska, M., Urakawa, T., Majiwa, P. A., Goddeerism B., \& Buscher, P. (2004). Variable surface glycoprotein RoTat 1.2 PCR as a specific diagnostic tool for the detection of Trypanosoma evansi infections. Kinetoplastid Biology and Disease, 3, 1-6.

Conrado, A. C., Lopes, S. T. A., Oliveira, L. S. S., Monteiro, S. G., Vargas, D. L. B., \& Bueno, A. (2005). Infecção natural por Trypanosoma evansi em cavalos na região central do estado do Rio Grande do Sul. Ciência Rural, 35, 928-931.

Corrêa, A. A. R., Nascimento, M. V., \& Faria, L. S. (2005). Babesiose canina: relato de caso. Revista Científica Eletrônica de Medicina Veterinária, (4), 1215 .

Costa, H. X. (2011). Interação de hemoparasitos e hemoparasitoses em casos clínicos de trombocitopenia em cães no município de Goiânia (Dissertação Mestrado em Medicina Veterinária). Universidade Federal de Goiás, Escola de Veterinária e Zootecnia, Goiânia, Brasil.

Costa, J. O. et al. (1973). Ehrlichia canis infections in dog in Belo Horizonte - Brazil. Arquivo da Escola Superior de Veterinária da Universidade de Minas Gerais. 25, -197 .

Cox F.E.Concomitant infections, parasites and immune responses. Parasitology, 122, S23-S38.

Criado-Fornelio, A., Ruas, J. L., Casado, N., Farias, N. A., Soares, M. P., Muller, G. ... Barba-Carretero, J. C. (2006). New molecular data on mammalian Hepatozoon species (Apicomplexa: Adeleorina) from Brazil and Spain. Journal of Parasitology, 92, 93-99.

Dias, V. A. C. M., \& Ferreira, F. L. A. (2016). Babesiose canina: Revisão. PUBVET, 10, 886-888.

Doyle, C. K., Labruna, M. B., Breitschwerdt, E.B., Tang, Y., Corstvet, R., Hegarty, B. C. ... McBride, J. W. (2005). Detection of medically important Ehrlichia by quantitative multicolor TaqMan real-time polymerase chain reaction of the dsb gene. Journal of Molecular Diagnostics, $7,504-510$.

Doyle, R. L., Silva, A. S., Monteiro, S. G., Santurio, J. M., \& Graça, D. L. (2007). Eficácia de medicamentos no controle da infecção experimental por Trypanosoma evansi em ratos. Acta Scientiae Veterinariae, 35, 67-71.

Ettinger, S., \& Feldman, E. (2014). Tratado de medicina interna veterinária: Doenças do cão e do gato. Guanabara Koogan.

Graham, A. L., Cattadori, I. M., Lloyd, J. O., Ferrari, M. J. \& Bjornstad, O. N.Transmission consequences of coinfection: cytokines writ large? Trends in Parasitology, 23, 284-291. 
Halkyer, N. O., \& Torres B. A. (2010). Enfermedad de Chagas en poblaciones prehistóricas del norte de Chile. Revista chilena de história natural, $531-541$.

Harrus, S., \& Waner, T. (2011). Diagnosis of canine monocytotropic ehrlichiosis (Ehrlichia canis): an overview. The Veterinary Journal, 187, $292-296$.

Hass, D. J., \& Torres, A. C. D. (2016). Aplicações das técnicas de PCR no diagnóstico de doenças infecciosas dos animais. Revista Científica de Medicina Veterinária, 14(26).

Herrera, H. M., Dávila, A. M. R., Norek, A., Abreu, U. G., Souza, S. S., D’Andrea, P. S., \& Jansen, A. M. (2004). Enzootiology of Trypanosoma evansi in Pantanal, Brazil. Veterinary Parasitology, 125(3-4), 263-275.

Inokuma, H., Okuda, M., Ohno, K., Shimoda, K., Onishi, T. (2002). Analysis of the 18SrRNA gene sequence of Hepatozoon detected in two japonese dogs. Veterinaria Parasitologia, 106, 265-271.

Isola, J., Cadioli, F. A., \& Nakage, A. P. (2012). Erliquiose canina - Revisão de literatura. Revista Eletrônica de Medicina Veterinária, n. 18.

Jain, N. C. (1993). Essentials of veterinary hematology (p. 417). Lea \& Febiger.

Leite, L. C., Cirio, S. M., Queiroz, V. S., Silva, M. A. N., Luz, E., Molinari, H. P. ... Zadorosnei, A. C. B. (2006). Dirofilariose canina: revisão de uma zoonose emergente. Revista Acadêmica, 4, 49-56.

Lima, A. P., Barçante, J. M. P., Boeloni, J. N., Bezerra, P. S., Jr., Wouters, F., Wouters, A. T. \& Seixas, J. N. (2017). Aspectos anatomopatológicos em cães naturalmente infectados pelo Hepatozoon canis. Pesquisa Veterinária Brasileira, 37, 145-149.

Lloyd, S. Environmental Influences on Host Immunity. In: Ecology of Infectious Diseases in Natural Populations, Grenfell \& Dobson, (eds). 1995.

Mathew, J. S., Bussche, V. D., Ewing, S. A., Malayer, J. R., Latha, B. R., \& Panciera, R. J. (2000). Phylogenetic relationships of Hepatozoon (Apicomplexa: Adeleorina) based on molecular, morphologic, and life-cyde characters. The Journal of Parasitology, 86, 366-372.

Melo, O. A., Jr., Miranda, F. J. B., Almeida, J., Albernaz, A. P., \& Machado, J. A. (2008). Hepatozoonose canina em Campos dos Goytacazes, RJ. Arquivos de Ciências Veterinárias e Zootecnia da UNIPAR, 11, 73-75.

Meyer, D. J., \& Harvey, J. W. (2004). Veterinary laboratory medicine: interpretation \& diagnosis. Sauders.

Michels, P.A. M., \& Hannaert, V. (1994). The evolution of kinetoplastid glycosomes. Journal of Bioenergetics and Biomembranes, 26, $213-219$.

Molocco, C., Kamyingkird, K., Desquesnes, M., Jittapalapong, S., Herbreteau, Y., Chaval, Y. ... \& Morand, S. (2012). Molecular demonstration of Trypanosoma evansi and Trypanosoma lewisi DNA in wild rodents from Cambodia, Lao PDR and Thailand. Transboundary and Emerging Diseases, 60, 1726.

Monteiro, S. G. (2014). Parasitose na medicina veterinária (p. 356). Roca.

Mundim, A. V. Mundim, M. J. S. \& Barbosa, F. C. (2002). Hepatozoonosis canina. Veterinária Noticias, 8, 141-151.

Mupanomunda, M.; et al. (1997). Dirofilaria immitis: heartworm infection alters pulmonary artery endothelial cell behavior. Journal of Applied Physiology, Bethesda, 82, 389-398.

Mylonakis, M. E., Koutinas, A. F., Baneth, G., Polizopoulou, Z., \& Fytianou, A. (2004). Mixed Ehrlichia canis, Hepatozoon canis and presuntive Anaplasma phagocytophilum infection in a dog. Veterinary clinical pathology, 33, 249-251.

Nelson, C. T. (2015). Principles of treatment: canine heartworm disease. Today's Veterinary Practice, 5, 53-59.

Nelson, R.W. \& Couto, C.G (2001). Fundamentos de medicina interna de pequenos animais. 2.ed. Rio de Janeiro: Guanabara Koogan.

Oliveira, J. S., Lemos, M., Vilela, D. C., Luciano, F. C., Borges, K. I. N., \& Braga, I. A. (2016, junho). Dirofilariose canina: primeiro relato de caso no município de Mineiros-GO. In Anais do I Colóquio Estadual de Pesquisa Multidisciplinar, Mineiros, Brasil.

Pimentel, J. L., Barbosa, M. A. G., \& Ferrer, M. T. (2013). Dirofilariose canina: Relato de caso. Xlll Jornada de Ensino, Pesquisa e Extensão - JEPEX 2013, Ufrpe.

Raina, A. K., Kumar, R., Rajora, V. S., Sridhar, \& Singh, R. P. (1985). Oral transmission of Trypanosoma evansi infection in dogs and mice. Veterinary Parasitology, 18, 67-69.

Silva, A. S., Ceolin, L. V., Oliveira, C. B., Monteiro, S. G., \& Doyle, R. L. (2007). Infecção via oral por Trypanosoma evansi em animais de laboratório. Ciência Rural, 37, 897-900.

Silva, A. S., Costa, M. M., Lopes, S. T. A., \& Monteiro, S. G. (2008). Alterações hematológicas em coelhos infectados experimentalmente pelo Trypanosoma evansi. Ciência Rural, 38, 538-542.

Silva, A. S., Pierezan, F., Wolkmer, P., Costa, M. M., Oliveiro, C. B., Tonin, A. A. \& Monteiro, S. G. (2010). Pathological findings associated with experimental infection by Trypanosoma evansi in cats. Journal of Comparative Pathology, 142, 170-176.

Silva, M. V. M., Fernandes, R. A., Nogueira, J. L., \& Ambrosio, C. E. (2011). Erliquiose canina: revisão de literatura. Arquivos de Ciências Veterinárias Zoologia, 14, 139-143.

Silva, R. A. M. S., Lima, E. S. S., Ramirez, L., \& Dávila, A. M. R. (2004). Profilaxia e Controle do Mal de Cadeiras em animais domésticos no Pantanal (1 ed.). Corumbá, MS: Embrapa Pantanal-Documentos (INFOTECA-E). 
Research, Society and Development, v. 10, n. 12, e393101220294, 2021

(CC BY 4.0) | ISSN 2525-3409 | DOI: http://dx.doi.org/10.33448/rsd-v10i12.20294

Silva, R. A. M. S., Seidi, A., Ramirez, L., \& Dávila, A. M. R. (2002). Trypanosoma evansi e Trypanosoma vivax: biologia, diagnóstico e controle. Corumbá, MT: Embrapa Pantanal, p. 141.

Silva, R. C. D., \& Langoni, H. (2008). Dirofilariose: zoonose emergente negligenciada. Ciência Rural, 39, 1615-1624.

Silveira, A. R. M. (2018). Dirofilariose canina - Revisão bibliográfica (33f. Dissertação - Mestrado Integrado em Medicina Veterinária). Escola Universitária Vasco da Gama, Coimbra, Portugal.

Simón, F., Siles-Lucas, M., Morchón, R., González-Miguel, J., Mellado, I., Carretón, E., \& Montoya-Alonso, J. A. (2012). Human and animal dirofilariasis: The emergence of a zoonotic mosaic. Clinical Microbiology Reviews, 25, 507-544.

Solano-Gallego, L. \& Baneth, G., (2011). Babesiosis in dogs and cats—Expanding parasitological and clinical spectra. Veterinary Parasitology, $181,48-60$.

Sousa, V. R. F., Almeida, A. B. P F., Barros, L. A., Sales, K. G., Justino, C. H. S., Dalcin, L., Bomfim, T. C. B. (2010) Avaliação clínica e molecular de cães com erliquiose. Ciência Rural, 40, 1309-1313.

Taylor, M. A., Coop, R. L., \& Wall, R. L. (2014). Parasitologia veterinária (3a ed.) Guanabara Koogan.

Vicent-Johnson, N. A., Macintire, D. K., Lindsay, D. S., Lenz, S. D., Baneth, G., Shkap, V., \& Blagburn, B. L. (1997). Uma nova espécie de hepatozoário em cães: descrição do agente causador da hepatozoonose canina na América do Norte. Journal Parasitology, 83, 1165-1172.

Voyvoda, H.; Pasa, S. \& Uner, A. Clinical Hepatozoon canis infection in a dog in Turkey. Journal of Small Animal Practice, 45, 613-617.

Yabsley, M. J., Mckibben, J., Macpherson, C. N., Cattan, P. F., Cherry, N. A., Hegarty, B. C. \& Sylvester, W. (2008). Prevalence of Ehrlichia canis, Anaplasma platys, Babesia canis vogeli, Hepatozoon canis, Bartonella vinsonii berkhoffii, and Rickettsia spp. in dogs from Grenada. Veterinary parasitology, 151, 279-285. 